- 5 Hawley DJ, Wolfe F, Cathey MA. Pain, functional disability, and psychological status: a 12-month study of severity in fibromyalgia. 7 Rheumatol 1988;15:1551-6.

6 Aromaa A, Heliövaara M, Impivaara $\mathrm{O}$, Knekt $\mathrm{P}$, Maatela J. The execution of the mini-Finland health survey. Part 1. Helsinki, Turku: Social Insurance Institution 1989 ML.88. In Finnish with English summary.

Kish L. Survey sampling. New York: Wiley, 1965.

8 Goldberg D. The detection of psychiatric illness by questionnaire. London: Oxford University Press, 1972. (Maudsley Monograph 21 .)

9 Takala J, Räkköläinen V. Salminen J, Sievers K. Mental health in the middleaged population. Acta Psvchiatr Scand 1979;59:294-305.

10 Wing JK, Cooper JE, Sartorius N. The measurement and classification of psychiatric symptoms. London: Cambridge University Press, 1974.
11 Haberman SJ. Analysis of qualtiative data. Vol 1 . Introductory topics. New York: Academic Press, 1978

12 Cox DR. Regression models and life tables (with discussion). Fournal of the Roval Statistical Society $(B)$ 1972; 74:187-220.

13 Forslind K, Fredriksson E, Nived O. Does primary fibromyalgia exist

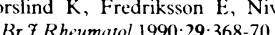

14 Goldenberg DL. Fibromyalgia and other chronic fatigue syndromes: is ther evidence for chronic viral disease? Semin Arthritis Rheum 1988;18:111-20. 15 Moldofsky $\mathrm{H}$. The contribution of sleep-wake physiology to fibromyalgia. In Fricton JR, Awad EA, eds. Advances in pain research and therapy. Vol 17 Myofascial pain and fibromyalgia. New York: Raven Press, 1990.
Winford Orthopaedic Hospital, Bristol Michael J F Fordyce, FRCS, orthopaedic registrar Allen S Baker, FRCs, senior orthopaedic registrar E Gerald Staddon, BSC, medical physicist

Correspondence to: Mr M J F Fordyce, Royal Cornwall Hospital (City),

Truro, Cornwall TR1 2HZ.

BMf 1991;303:219-20

\title{
Efficacy of fixed minidose warfarin prophylaxis in total hip replacement
}

\author{
Michael J F Fordyce, Allen S Baker, Gerald E Staddon
}

\section{Abstract}

Objective-To determine whether a small fixed perioperative dose of warfarin would prevent deep vein thrombosis after total hip replacement.

Design-Prospective, randomised, double blind placebo controlled trial.

Setting-Winford Orthopaedic Hospital, Bristol.

Subjects -148 patients having primary total hip replacement.

Intervention-Warfarin $1 \mathrm{mg}$ given daily for one week before and three weeks after surgery.

Main outcome measure-Deep vein thrombosis diagnosed by the iodine-125 labelled fibrinogen uptake method.

Results-Deep vein thrombosis occurred in 25 $34 \%)$ of the patients given warfarin and $19(26 \%)$ of the controls (difference $8 \% ; 95 \%$ confidence interval $-6 \cdot 8 \%$ to $22 \cdot 8 \%$ ).

Conclusion-Fixed minidose warfarin does not prevent deep vein thrombosis after total hip replacement.

\section{Introduction}

The incidence of thromboembolism is particularly high after total hip replacement. Deep vein thrombosis occurs in up to $70 \%$ of patients. ${ }^{1}$ The incidence of the postphlebitic limb syndrome complicating thrombosis after hip replacement is unknown but may be as high as $51 \%$, which occurs after long bone fractures. ${ }^{2}$ Subclinical pulmonary emboli occur in up to $23 \%$ of patients, ${ }^{3}$ and $1-2 \%$ of patients die of pulmonary embolism.

Many prophylactic regimens have been described but none have proved ideal and there is no consensus on the most suitable prophylaxis. ${ }^{5}$ Several studies found that low dose heparin was effective, ${ }^{67}$ but Sikorski et al suggested that this regimen may only delay the onset of thromboembolic complications, describing a rebound surge in thromboembolism once heparin was stopped. ${ }^{8}$ Other studies found low dose heparin to be ineffective. ${ }^{910}$ Conventional ful dose anticoagulation begun before surgery is highly effective in preventing thromboembolism ${ }^{11}$ but has never been widely accepted because of the risks. ${ }^{4}$

A recent report of the success of fixed minidose warfarin in gynaecological patients ${ }^{12}$ prompted us to test its efficacy after total hip replacement. The advantages of this simple regimen were that there were no haemorrhagic complications; prescription was by a daily fixed dose; and prophylaxis was continued after discharge from hospital, covering the period when $60 \%$ of fatal pulmonary emboli are likely to occur. ${ }^{11}$

\section{Patients and methods}

The study was modelled on projected estimations from the report of Poller et al. ${ }^{12}$ We were seeking to detect a reduction in deep vein thrombosis from $50 \%$ to $20 \%$. For the power of the study $(1-\beta)$ to reach $90 \%$ we required 75 patients in each group.

One hundred and forty eight patients who were having primary total hip replacement were randomly allocated to either the treatment group or the control group. The treatment group received $1 \mathrm{mg}$ warfarin daily for one week before and three weeks after surgery. The control group received placebo for the same period. Randomisation was achieved by the use of random number tables by the hospital pharmacy, which prepared the tablets in foil packets. Thus neither the patients nor the investigators were aware of which group the patient was in. Prothrombin time, activated partial thromboplastin time, platelet count, and haemoglobin concentration were assessed at two weeks and at 24 hours preoperatively and 48 hours postoperatively. Patients were excluded if there was a history of thromboembolism or a medical contraindication to warfarin. Smoking history was not recorded. All patients gave fully informed consent.

All the hip arthroplasties were performed in the lateral decubitus position by either the posterior or direct lateral approach. Patients received a standardised general anaesthetic. Wounds were closed with subcuticular suture. Two $6 \mathrm{~mm}$ suction drains were used. Intraoperative blood loss was estimated and postoperative drainage and the volume of blood transfused were recorded.

Diagnosis of deep vein thrombosis-All patients were screened for deep vein thrombosis by the iodine-125 labelled fibrinogen uptake method..$^{113}$ The thyroid was protected by oral potassium iodide ( $100 \mathrm{mg}$ daily). Each patient received $3.7 \mathrm{MBq}(100 \mu \mathrm{Ci}){ }^{125} \mathrm{I}$-fibrinogen on the morning after surgery. Daily scanning of radioactivity at nine points ${ }^{13}$ on both legs ${ }^{10}$ was performed either until discharge or until two weeks postoperatively. Deep vein thrombosis was diagnosed in the calf or popliteal veins when the ${ }^{125} I$-fibrinogen count was raised by at least $20 \%$ over one or more points and this increase persisted over two consecutive days. Any suspected thrombosis in the femoral vein was further investigated by phlebography as postoperative haematoma may cause a false positive increase in radioactivity in that region. Patients with thrombosis in the popliteal vein or more proximally received full anticoagulant treatment.

Wound complications-All wounds were inspected and scored clinically at one week. Wounds were judged to be clean, moist, or inflamed. Haematomas were sought with a real time ultrasound machine with a 
TABLE I-Comparisons of fixed minidose warfarin and control groups. Except where stated otherwise figures are numbers (percentages) of patients

\begin{tabular}{|c|c|c|}
\hline & $\begin{array}{l}\text { Fixed minidose } \\
\text { warfarin group } \\
\quad(n=74)\end{array}$ & $\begin{array}{c}\text { Control group } \\
(n=74)\end{array}$ \\
\hline Mean age (years) (range) & $68(41-86)$ & $67(38-86)$ \\
\hline Men & $56(75 \cdot 7)$ & $48(64 \cdot 9)$ \\
\hline Women & $18(24 \cdot 3)$ & $26(35 \cdot 1)$ \\
\hline Mean obesity score` & 3 & 3 \\
\hline \multicolumn{3}{|l|}{ Type of arthroplasty: } \\
\hline Uncemented & $10(13 \cdot 5)$ & $11(14 \cdot 9)$ \\
\hline Cemented & $64(86 \cdot 5)$ & $63(85 \cdot 1)$ \\
\hline Mean operation time (min) & 96 & 98 \\
\hline \multicolumn{3}{|l|}{ Diagnosis: } \\
\hline Osteoarthritis & $73(98 \cdot 6)$ & $69(93 \cdot 2)$ \\
\hline Rheumatoid arthritis & $1(1.4)$ & $5(6.8)$ \\
\hline Varicose veins & $18(24 \cdot 3)$ & $14(18.9)$ \\
\hline \multicolumn{3}{|l|}{ Surgical approach: } \\
\hline Posterior & $39(52 \cdot 7)$ & $31(41 \cdot 9)$ \\
\hline Direct or anterolateral & $35(47 \cdot 3)$ & $43(58 \cdot 1)$ \\
\hline
\end{tabular}

${ }^{\star}$ Calculated with weight and height tables: underweight $=1$; acceptable weight $=2$; overweight $=3$; obese $=4$.

TABLE II-Blood loss and complications among patients in the two operated groups. Except where stated otherwise figures are numbers (percentages) of patients

\begin{tabular}{lcc}
\hline & $\begin{array}{c}\text { Fixed minidose } \\
\text { warfarin group } \\
(\mathbf{n}=74)\end{array}$ & $\begin{array}{c}\text { Control group } \\
(\mathbf{n}=74)\end{array}$ \\
\hline Mean blood loss (ml) & 1388 & 1439 \\
Mean units of blood transfused & $2 \cdot 5$ & $2 \cdot 5$ \\
Mean haemoglobin deficit $(\mathrm{g} / \mathrm{l})$ & $15 \cdot 0$ & $13 \cdot 0$ \\
Deep vein thrombosis: & $25(33 \cdot 8)^{\star}$ & $19(25 \cdot 7)^{\star}$ \\
$\quad \begin{array}{l}\text { Present } \\
\text { Absent }\end{array}$ & $49(66 \cdot 2)$ & $55(74 \cdot 3)$ \\
Pulmonary embolism & $5(6 \cdot 8)$ & $3(4 \cdot 1)$ \\
Wound sepsis & 0 & $1(1 \cdot 4)$ \\
Wound haematoma (>20 ml) detected & $6(8 \cdot 1)$ & $8(10 \cdot 8)$ \\
$\quad$ by ultrasound & $8 \cdot 4$ & $8 \cdot 5$ \\
Mean No of fibrinogen scans & $6(8 \cdot 1)$ & $5(6 \cdot 8)$ \\
Femoral vein thrombosis confirmed by & phlebography & \\
\hline
\end{tabular}

Difference in incidence $8 \cdot 1 \%$ (95\% confidence interval $-6 \cdot 8 \%$ to $22 \cdot 8 \%$ ).

$5 \mathrm{MHz}$ transducer. ${ }^{14}$ A significant haematoma was judged to be one calculated to be more than $20 \mathrm{ml}$.

Follow up-All patients were reviewed six weeks after operation to ascertain whether any thromboembolic episodes had occurred since discharge.

\section{Results}

The treatment and control groups were comparable with respect to age, sex, obesity score, type of joint replacement, operative time, diagnosis, prevalence of varicose veins, and surgical approach (table I). Blood loss, transfused blood volume, haemoglobin deficit, and incidences of wound sepsis and haematoma were also similar (table II). Deep vein thrombosis was detected in $34 \%$ of patients $(n=25)$ in the treatment group and $26 \%$ of patients $(n=19)$ in the control group (difference $8 \%$; $95 \%$ confidence interval $-6.8 \%$ to $22 \cdot 8 \%)$.

\section{Discussion}

The ${ }^{125}$ I-fibrinogen technique was used in this trial to detect deep vein thrombosis because it offers a safe method of observing thromboembolic activity in the leg veins over a prolonged period. A modification of the original technique of Kakkar et $a l^{13}$ was used as described by Hampson et al. ${ }^{10}$ Because of its relative inaccuracy in the femoral vein segment any suggestion of an abnormal scan count in that segment was followed with a phlebogram before deep vein thrombosis was confirmed.

We found that a prophylactic regimen using $1 \mathrm{mg}$ warfarin daily perioperatively had no effect on the incidence of fibrinogen positive scans in the leg veins of patients having total hip replacement. The overall rate of thrombosis was $30 \%$, which was considerably lower than the collective mean incidence of $59 \%$ gleaned from 14 studies in the 1970s. ${ }^{1}$ The difference may reflect the more modern practice of early mobilisation and shorter operating times.

The confusion on the issue of prophylaxis against deep vein thrombosis after total hip replacement is reflected by the current policy of prophylaxis used by British orthopaedic surgeons. Some $50 \cdot 4 \%$ still take no routine prophylactic precautions for their patients and only $19 \cdot 4 \%$ use anticoagulants.

Our findings support the thesis that deep vein thrombosis after total hip replacement is more resistant to prevention than deep vein thrombosis after other types of surgery. We conclude that fixed minidose warfarin is unlikely to afford any useful prophylaxis against complications of thromboembolism in patients having total hip replacement and therefore that this regimen cannot be recommended for prophylaxis in these patients.

1 Bergqvist D. Postoperative thromboembolism. Berlin: Springer-Verlag, 1983:20.

2 Aitken RJ, Mills C, Immelman EJ. The postphlebitic syndrome following shaft fractures of the leg. F Bone foint Surg 1987;69B:775-8.

3 Harris WH, McKusik K, Athanasonlis CA, et al. Detection of pulmonary emboli after total hip replacement using serial $\mathrm{C}^{15} \mathrm{O}_{2}$ pulmonary scans. 7 Bone foint Surg 1984;66A:1388-93.

4 Johnson R, Green JR, Charnley J. Pulmonary embolism and its prophylaxis following Charnley total hip replacement. Clin Orthop 1977;127:123-32.

5 Brenkel IJ, Clancy MJ. Total hip replacement and antithrombotic prophylaxis. Brf Hosp Med 1989;42:282-4.

- 6 Harris WH, Salzman EW, Athanasonlis CA, et al. Comparison of warfarin, low molecular weight dextran, aspirin, and subcutaneous heparin in prevention of venous thromboembolism following total hip replacement. I Bone foint Surg 1974;56A: 1552-62.

7 Morris GK, Henry APJ, Preston BJ. Prevention of deep vein thrombosis by low dose heparin in patients undergoing total hip replacement. Lancet 1974;ii:797-800.

8 Sikorski JM, Hampson WG, Staddon GE. The natural history and aetiology of deep vein thrombosis after total hip replacement. 7 Bone foint Surg 1981;63B:171-7.

9 Evarts CM, Alfidi RJ. Thromboembolism after total hip reconstruction. Failure of low doses of heparin in prevention. FAMA 1973;225:515-6.

10 Hampson WGJ, Harris FC, Lineas HK, et al. Failure of low-dose heparin to prevent deep vein thrombosis after total hip replacement arthroplasty. Lancet 1974;ii:795-7.

11 Sevitt S, Gallagher NG. Prevention of venous thrombosis and pulmonary embolism in injured patients. A trial of anticoagulant prophylaxis with phenindione in middle aged and elderly patients with fractured necks of femur. Lancet 1959;ii:981-9.

12 Poller L, McKernan A, Thompson JM, et al. Fixed minidose warfarin: a new approach to prophylaxis against venous thrombosis after major surgery. BMF 1987;295:1309-13.

13 Kakkar VV, Nicolaides AN, Renney JTG, et al. ${ }^{12}$ I-labelled fibrinogen test adapted for route screening for deep vein thrombosis. Lancet 1970;i:540-2. 14 Magnussen PA, Crozier AE, Gregg PJ. Detecting haematomas by ultrasound; brief report. F Bone foint Surg 1988;70B: 150.

(Accepted 10 May 1991)

\section{Correction}

Bone density in women receiving depot medroxyprogesterone acetate for contraception

In this paper by Cundy et al (6 July, p 13) figure 1 was incorrectly labelled. A correct version is given below.

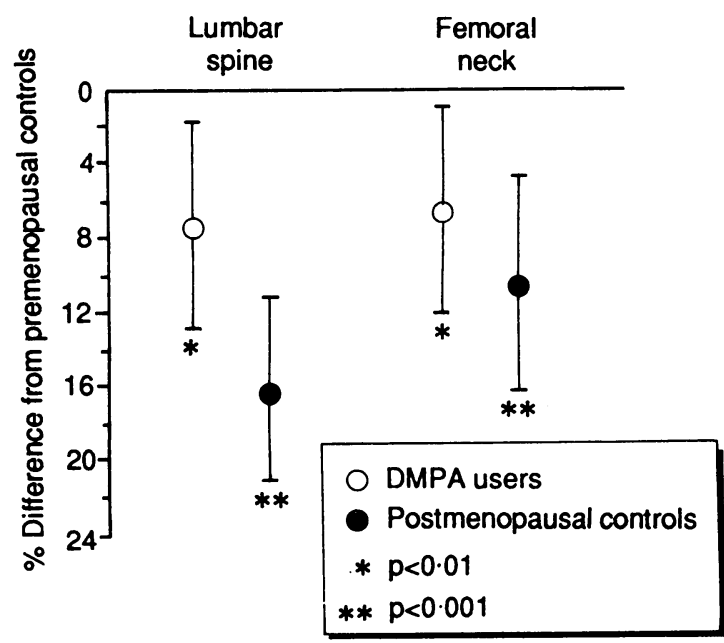

